\title{
PERANCANGAN APLIKASI INFOGRAFIS INTERAKTIF PENGENALAN FAKULTAS DAN JURUSAN UNIVERSITAS BUDI LUHUR
}

\author{
Niila Madaniyya ${ }^{1)}$, Mohamad Salman Alfarisi ${ }^{2)}$ \\ ${ }^{1}$ Manajemen Informatika, Fakultas Teknologi Informasi, Universitas Budi Luhur \\ ${ }^{1,2} \mathrm{Jl}$. Raya Ciledug, Petukangan Utara, Kebayoran Lama, Jakarta Selatan 12260 \\ E-mail : nmadaniyya@gmail.com ${ }^{1)}$, salman.alfarisi@budiluhur.ac.id ${ }^{2)}$
}

\begin{abstract}
Abstrak
Desain aplikasi ini dimaksudkan sebagai sebuah terobosan baru dalam media informasi dan promosi. Media promosi dan informasi dirancang dengan menggunakan infografis interaktif yang padat informasi tetapi menarik dan tidak membosankan. Dalam memproses sebuah informasi secara visual seperti lewat penggunaan ilustrasi, infografis dan video, otak manusia akan lebih cepat memproses informasi bahkan sampai 60.000 lebih cepat dan akan meningkat 20\% daripada sekedar menggunakan teks dan foto saja. Dalam penelitian ini, aplikasi infografis interaktif dibuat sebagai wadah informasi dan promosi terkait fakultas dan jurusan yang ada di Universitas Budi Luhur yang bertujuan untuk dapat menarik banyak pendaftar untuk kuliah di Universitas Budi Luhur. Bedasarkan penelitian pada bagian Penerimaan Mahasiswa Baru Universitas Budi Luhur, belum diterapkannya media informasi dan promosi yang dengan menggunakan multimedia interaktif. Metode yang digunakan penulis adalah observasi dan wawancara terhadap pihak Penerimaan Mahasiswa Baru Universitas Budi Luhur dan studi pustaka. Media yang digunakan merupakan gabungan dari tulisan, gambar, video, animasi, interaktifitas serta musik sehingga menghasilkan suatu program yang disebut multimedia interaktif. Hasil dari penulisan laporan ini berupa infografis interaktif pengenalan fakultas dan jurusan yang terdapat di Universitas Budi Luhur dalam bentuk format exe dan swf. Selain itu, penulis membuat Stationary berupa notebook spiral dan Merchandise berupa stiker.
\end{abstract}

Kata kunci: Infografis Interaktif, Media Informasi, Media Promosi, Multimedia Interaktif

\section{PENDAHULUAN}

\subsection{Latar Belakang}

Pada era teknologi internet dimana banyak dan begitu mudahnya informasi yang masuk ke otak manusia, manusia memiliki keterbatasan waktu dan energi untuk memahami maupun membaca informasi yang disampaikan. Dengan banyaknya distraksi, perhatian konsumen merupakan aset yang penting. Perusahaan harus berusaha untuk mendapatkan perhatian dari target konsumen.

Dalam memproses sebuah informasi secara visual seperti lewat infografis interaktif, otak kita akan lebih cepat memproses informasi bahkan sampai 60.000 lebih cepat dan akan meningkat 20\% dari apa yang di baca daripada sekedar menggunakan teks saja ${ }^{[1]}$ karena didalamnya terdapat interaktifitas dan beberapa unsur audiovisual seperti teks, gambar, animasi, video dan suara ${ }^{[2] .}$

Permasalahan yang di hadapi Bagian Penerimaan Mahasiswa Baru Universitas Budi Luhur adalah kurangnya perhatian dari target audience terhadap media informasi dan promosi yang digunakan yaitu brosur. Brosur dirasa kurang efektif karena biaya cetak yang tidak murah tetapi target pendaftar tidak tercapai. Oleh karena itu, berdasarkan permasalahan diatas dan juga sebagai universitas yang mempunyai visi menjadi universitas unggul dengan standar dengan ditopang teknologi informasi dan komunikasi, media informasi dan promosi berbentuk infografis interaktif ini bisa mengatasi masalah dan mewujudkan visi tersebut.

Dibandingkan brosur yang hanya sekali lihat lalu dibuang, infografis interaktif ini bisa ditempatkan di ruangan Penerimaan Mahasiswa Baru sebagai sumber dari informasi fakultas dan jurusan bagi calon pendaftar yang ingin sekedar bertanya ke staf yang sedang bertugas lalu staf tersebut bisa langsung mengarahkan dan menjawab pertanyaan pendaftar dengan menggunakan media infografis interaktif sebagai alat bantu saat menjelaskan detilnya kepada calon pendaftar tersebut sehingga proses tersebut berlangsung dengan cepat. Selain itu, aplikasi ini juga dapat ditampilkan pada acara promosi universitas seperti education expo dan pameran-pameran lainnya untuk memberikan kesan bahwa Universitas Budi Luhur adalah universitas yang modern dan bisa menarik minat pengunjung untuk tertarik untuk berkunjung ke booth Universitas Budi Luhur dan mencoba aplikasi tersebut. Selain menjadi aplikasi khusus desktop, aplikasi ini bisa dimasukkan ke website PMB Universitas Budi Luhur tetapi fitur nya akan terbatas dibandingkan dengan dibuka di desktop. 


\subsection{Rumusan Masalah}

Berdasarkan latar belakang yang telah dikemukakan, maka dapat diidentifikasi permasalahan dalam riset ini, yaitu sebagai berikut:

a. Belum ada aplikasi infografis interaktif sarana informasi dan promosi pada bagian Penerimaan Mahasiswa Baru (PMB) Universitas Budi Luhur.

b. Stationary masih belum lengkap variannya.

c. Merchandise masih kurang beragam jenisnya.

\subsection{Tujuan Riset dan Penulisan}

a. Mengembangkan aplikasi infografis interaktif.

b. Mengembangkan dan menambah media informasi dan promosi pengenalan jurusan bagi PMB Universitas Budi Luhur.

c. Sebagai bentuk penerapan dan pengaplikasian ilmu yang telah didapat.

d. Sebagai syarat untuk menyelesaikan jenjang pendidikan diploma 3.

\subsection{Batasan Masalah}

a. Riset ini hanya mengembangkan aplikasi infografis interaktif dengan tema bahasan yaitu fakultas dan jurusan yang ada di Universitas Budi Luhur.

b. Stationary yang dibuat berupa notebook spiral.

c. Merchandise yang dibuat berupa stiker.

\section{METODE PENELITIAN}

\subsection{Pengumpulan data}

Melakukan proses pengumpulan data-data yang terkait dengan riset. Metode pengumpulan data dilakukan dengan dua cara yaitu:

1) Wawancara (Interview)

Wawancara dilakukan untuk mendapatkan informasi secara langsung dengan cara tanya jawab kepada Bagian Penerimaan Siswa Baru (PMB) Universitas Budi Luhur.

2) Studi Pustaka

Studi Pustaka dilakukan dengan menggunakan buku, literatur, maupun dari internet sebagai sumber bacaan yang terkait dengan penulisan laporan.

\subsection{Analisa data dan perancangan}

Menganalisa data yang sudah terkumpul untuk diterapkan dengan mencocokan kebutuhan dari tempat riset lalu membuat sketsa desain rancangan aplikasi.

\subsection{Implementasi}

Setelah data terkumpul, penulis mulai membuat aplikasi infografis interaktif berdasarkan sketsa rancangan yang telah dibuat.

\section{HASIL DAN PEMBAHASAN}

3.1. Spesifikasi Teknologi Hardware

Berikut adalah spesifikasi Hardware yang digunakan dalam pembuatan aplikasi ini:

Tabel 1. Tabel Hardware Pendukung

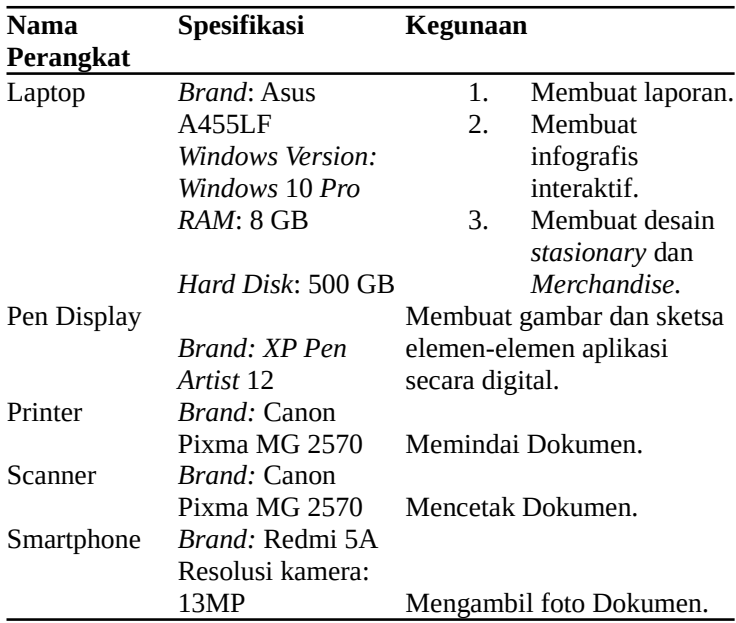

\subsection{Spesifikasi Teknologi Software}

a. Adobe InDesign CC 2019

Adobe InDesign adalah Software yang dikembangkan oleh perusahaan Adobe System yang digunakan untuk publishing dan typesetting. Software ini mulanya digunakan untuk membuat poster, brosur, majalah, koran, presentasi, buku serta buku elektronik (e-books). Tetapi kini Adobe InDesign bisa digunakan untuk membuat buku, aplikasi atau game interaktif sederhana.

Penulis menggunakan Software Adobe InDesign untuk menyatukan semua asset vector dan memberi animasi serta interaksi.

b. Adobe Illustrator CC 2019

Adobe Illustrator adalah Software yang dikembangkan oleh perusahaan Adobe System yang diperuntukan untuk membuat dan mengedit grafis berbasis vektor.

Penulis menggunakan Software Adobe Illustrator untuk Membuat seluruh asset vektor yang ada di dalam infografis.

c. Filmora

Filmora adalah Software untuk edit video. Penulis menggunakan filmora untuk meng-edit video yang diperoleh dari youtube official Budi Luhur untuk dimasukkan ke dalam aplikasi. 


\subsection{Analisis Objek}

Aplikasi infografis interaktif ini bisa menjadi media informasi dan promosi yang menarik dan efektif karena penyajian infromasi tidak hanya menggunakan foto dan teks saja tetapi dengan gabungan gambar illustrasi, video, animasi dan interaktifitas.

Kendala yang dihadapi dalam pembuatan infografis interaktif ini terletak dibagian desain dan ilustrasinya. Ilustrasi infografis dibuat semenarik mungkin tetapi tetap sederhana dan informatif sedangkan desain keseluruhan harus konsisten agar keharmonisan visual tetap terjaga dengan penerapan user experience yang baik.

\subsection{Rancangan Aplikasi}

Rancangan layar berukuran lebar 1145 pixel dan panjang 641 pixel. Desain intro awal hanya berupa logo Universitas Budi Luhur yang di animasikan dengan efek grow dan fade out, setelah animasi logo selesai, muncul tampilan menu start dengan desain Gedung Universitas Budi Luhur dan animasi sederhana.

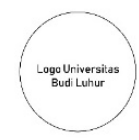

Gambar 1. Tampilan Rancangan Layar Intro Logo

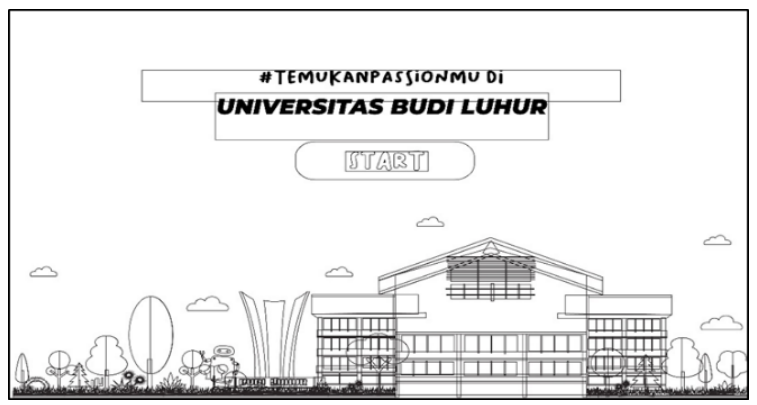

Gambar 2. Tampilan Rancangan Layar Start

Untuk layout keseluruhan aplikasi seperti gambar dibawah, terdapat gabungan dari video, hyperlink, tulisan, animasi karakter, gambar / icon dan animasi dekoratif. Infografis interaktif ini memuat penjelasan jurusan, konsentrasi jurusan, video fakultas dan konsetrasi dari jurusan terkait yang sumbernya didapat dari bagian Penerimaan Mahasiswa Baru (PMB) Universitas Budi Luhur.
Layout dibawah ini berlaku untuk keseluruhan menu fakultas kecuali ASTRI.

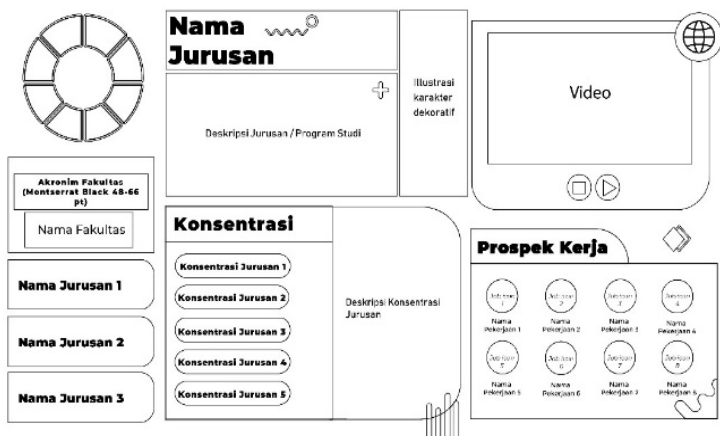

Gambar 3. Tampilan Rancangan Layar Menu Semua Fakultas

Untuk layout ASTRI menggunakan seperti gambar dibawah ini karena ASTRI adalah akademi khusus sekretari yang hanya mempunyai satu program studi dan konsentrasi.

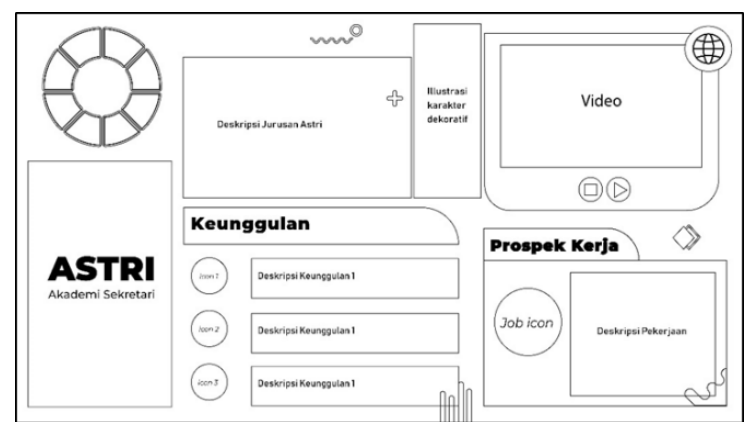

Gambar 4. Tampilan Rancangan Layar Menu Khusus ASTRI

\subsection{Konsep Desain Ajuan}

a. Bentuk

1) Desain infografis interaktif Tampilan infografis interaktif yang mudah digunakan oleh user.

2) Merchandise Desain Merchandise berupa stiker dengan desain masing-masing fakultas yang terdapat di instansi.

3) Stationary Desain Stationary berupa notebook spiral berlogo instansi.

b. Warna

Aplikasi ini menggunakan warna dengan value yang tinggi hingga sedang dengan saturasi agak tinggi, dan meminimalisir penggunaan warna-warna yang gelap seperti hitam, coklat tua, dan warna dengan saturasi yang rendah yang bertujuan untuk membangun mood dan perasaan positif yang menyenangkan bagi usia sekitar 17-20 tahun. 


\subsection{Material}

a. Jenis Bahan yang Digunakan

Dalam pembuatan Merchandise stiker menggunakan material kertas stiker vinyl sedangkan pada Stationary yaitu notebook spiral menggunakan karton tebal hard cover dengan finishing glossy isi 50 halaman polos.

b. Teknik Cetak

Teknik cetak untuk stiker menggunakan teknik digital printing. Teknik cetak untuk notebook spiral menggunakan print digital untuk cetak desain covernya dan menggunakan teknik spiral binding untuk penjilidannya.

c. Alasan Penggunaan Bahan Pada Produk Jadi Penggunaan material vinyl pada stiker yaitu bahan vinyl mempunyai permukaan doff, tidak terlalu tipis dan harganya terjangkau sedangkan pada Stationary yaitu notebook spiral menggunakan bahan karton tebal hard cover dengan finishing glossy sehingga terlihat lebih berkualitas.

\subsection{Tampilan Sistem}

Berikut ini adalah user interface pengguna dari Infografis Interaktif pengenalan fakultas dan jurusan Universitas Budi Luhur yang dimulai dari intro kemudian ke menu start setelah itu akan muncul tampilan menu masing-masing fakultas mulai dari Fakultas Teknologi Informasi (FTI), Fakultas Ilmu Komunikasi (FIKOM), Fakultas Ekonomi dan Bisnis (FEB), Fakutas Ilmu Sosial dan Politik (FISIP), Fakultas Teknik (FT), Akademi Sekretari (ASTRI), Pascasarjana, hingga D3 Unggulan. Rancangan layar tersusun dengan format urutan Fakultas terlebih dahulu, lalu ke program studi dan dipersempit lagi ke konsentrasi yang dimiliki program studi tersebut dengan format nama: Fakultas-Program Studi-Konsentrasi.

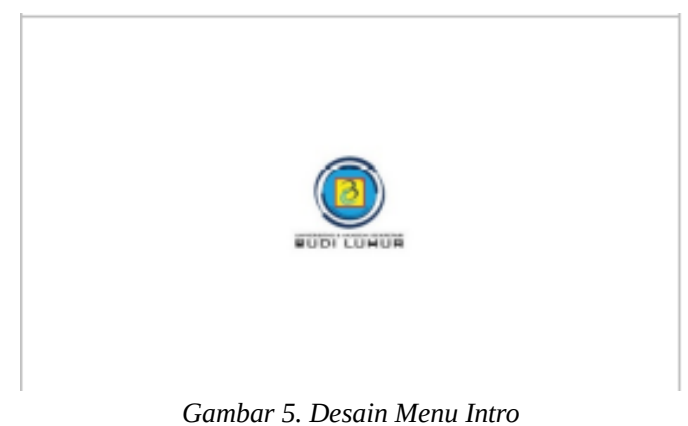

Tampilan Layar desain menu intro. Hanya berupa logo Univeritas Budi Luhur dengan animasi zoom dan fade out.

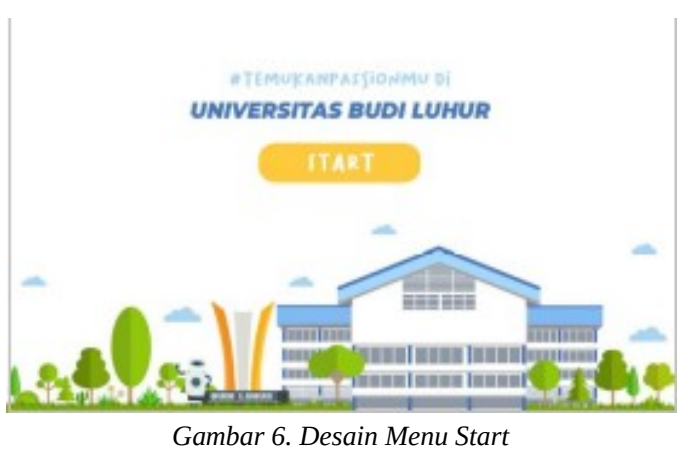

Tampilan Layar desain menu Start dengan satu button bernama start untuk masuk ke menu fakultas dan jurusan. Dihiasi oleh animasi dan illustrasi gedung Universitas Budi Luhur.

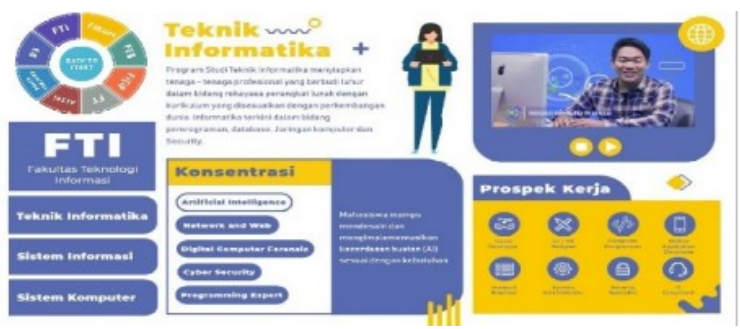

Gambar 7. Contoh Desain Menu FTI-Teknik Informasi-Artificial Intelligence

Tampilan Layar desain menu Fakultas Teknologi Informasi (FTI) yang berisi Program studi dan konsentrasi yang terdapat di FTI. Didesain menggunakan warna official FTI.

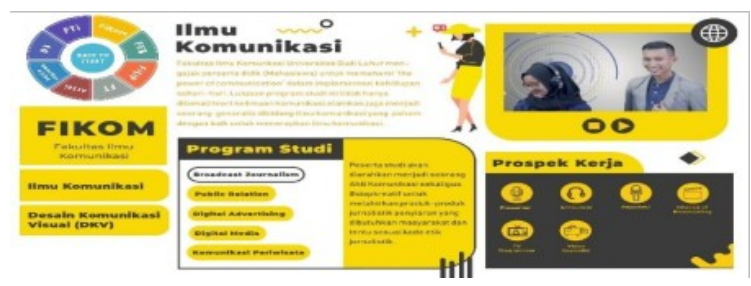

Gambar 8. Contoh Desain Menu FIKOM-Ilmu KomunikasiBroadcast journalism

Tampilan Layar desain menu Fakultas Ilmu Komunikasi (FIKOM) yang berisi Program studi dan konsentrasi yang terdapat di FIKOM. Didesain menggunakan dengan warna official FIKOM.

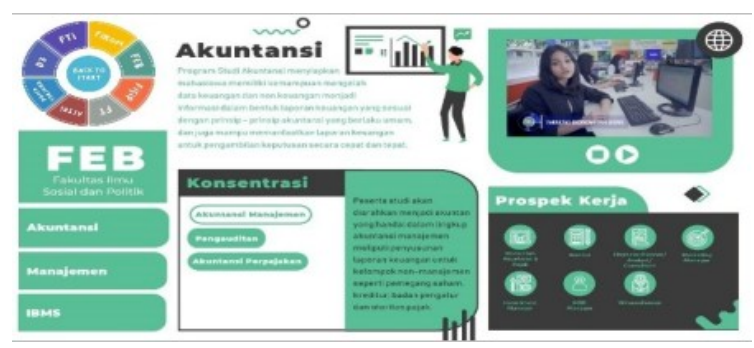

Gambar 9. Contoh Desain Menu FEB-Akuntansi-Akuntansi Manajemen 
Tampilan Layar desain menu Fakultas Ekonomi dan Bisnis (FEB) yang berisi Program studi dan konsentrasi yang terdapat di FIKOM. Didesain menggunakan warna official FIKOM.

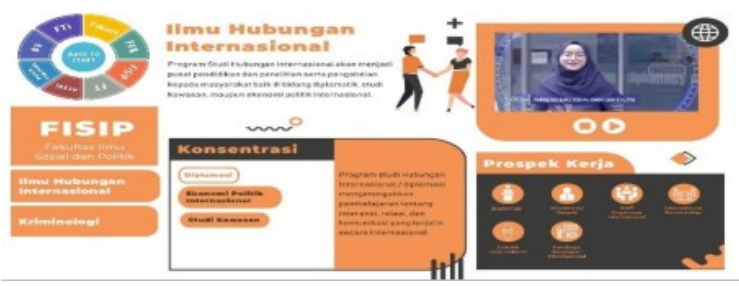

Gambar 10. Contoh Desain Menu FISIP-HI-Diplomasi

Tampilan Layar desain menu Fakultas Ilmu Sosial dan Politik (FISIP) yang berisi Program studi dan konsentrasi yang terdapat di FISIP. Didesain menggunakan warna official FISIP.

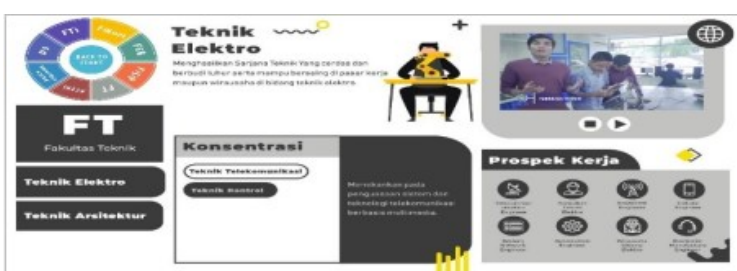

Gambar 11. Contoh Desain Menu FT-Teknik Elektro-Teknik Telekomunikasi

Tampilan Layar desain menu Fakultas Teknik (FT) yang berisi Program studi dan konsentrasi yang terdapat di FT. Didesain menggunakan warna official FT.

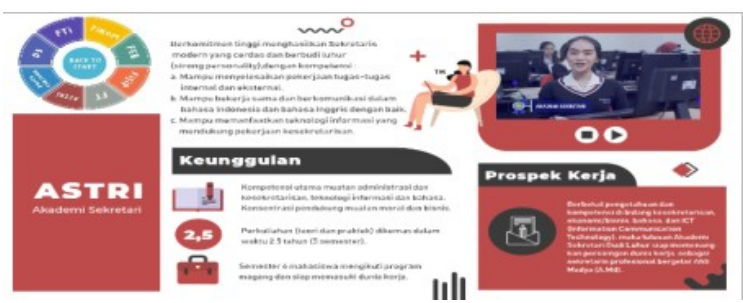

Gambar 12. Contoh Desain Menu ASTRI

Tampilan Layar desain menu Akademi Sekretari (ASTRI) yang berisi penjelasan dari ASTRI.

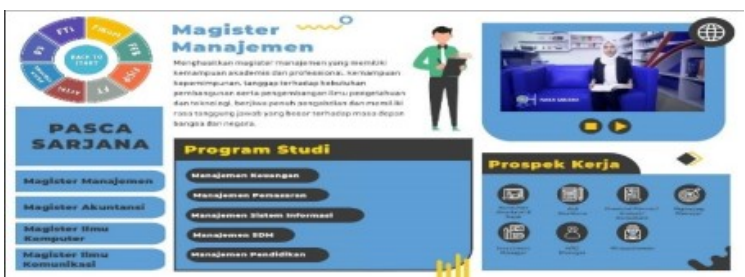

Gambar 13. Contoh Desain Menu Pascasarjana-Magister Manajemen

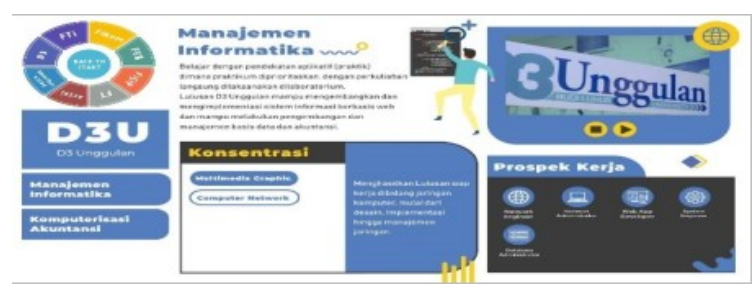

Gambar 14. Contoh Desain Menu D3-Manajemen InformatikaComputer Network

Tampilan Layar desain menu D3 Unggulan (D3U) yang berisi Program studi dan konsentrasi yang terdapat di D3U. Didesain menggunakan warna official D3U.

\subsection{Tampilan Produk Jadi}

Berikut ini adalah gambar Mock Up dari desain Stationary yaitu Notebook Spiral dari sisi depan dan sisi perspektif samping dan juga gambar dari desain awal Merchandise yaitu Stiker sebelum masuk ke proses cetak.

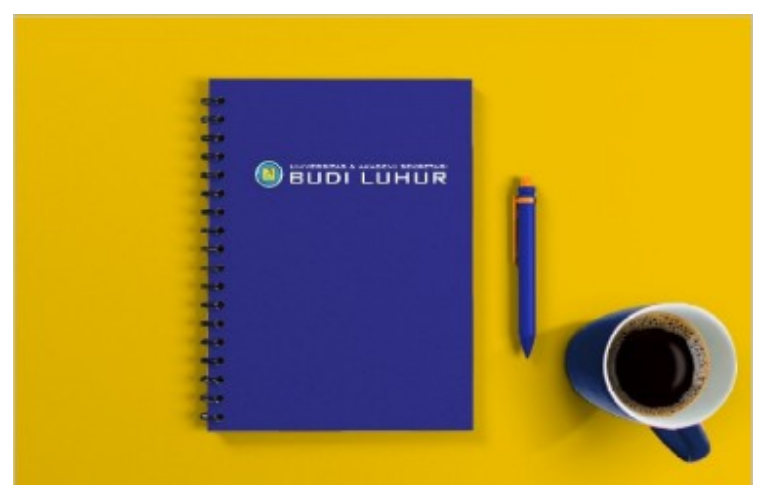

Gambar 15. Desain Notebook Spiral-Tampak Depan

Notebook didesain sedemikian rupa menggunakan logo Universitas Budi Luhur dan warna biru sebagai warna officialnya.

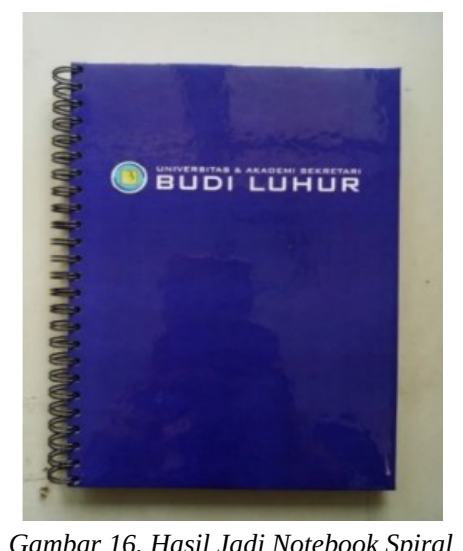

Gambar 16. Hasil Jadi Notebook Spiral 


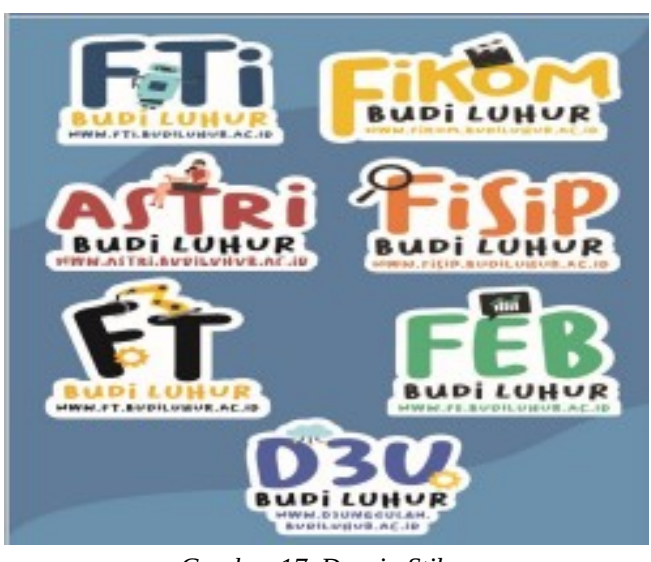

Gambar 17. Desain Stiker

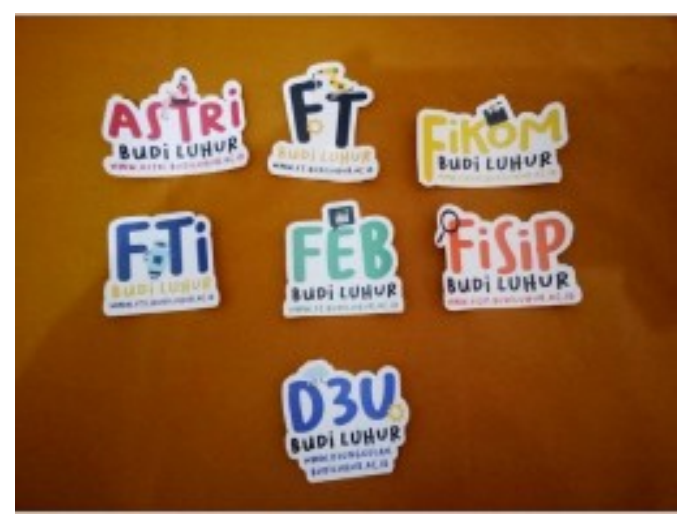

Gambar 18. Hasil Jadi Stiker

Stiker didesain dengan menggunakan gaya ilustrasi desain flat. Dibuat7 desain yang masingmasing melambangkan berbgai fakultas yang terdapat di Universitas Budi Luhur.

\section{KESIMPULAN}

Berdasarkan hasil penelitian dan pembahasan pada bab-bab sebelumnya, maka dapat diambil kesimpulan sebagai berikut:

a. Aplikasi infografis interaktif yang sudah dibuat dapat langsung digunakan oleh bagian Penerimaan Mahasiswa Baru Universitas Budi Luhur agar target audience dapat menyerap informasi dengan lebih cepat.

b. Stationary yang dibuat berupa notebook spiral karena belum ada di Universitas Budi Luhur dan dapat digunakan oleh siapapun baik dosen, mahasiswa, maupun staf Universitas Budi Luhur.

c. Merchandise yang dibuat berupa stiker karena belum ada di Universitas Budi Luhur dan juga sebagai alat promosi untuk memperkenalkan fakultas yang terdapat di Universitas Budi Luhur.

Adapun saran-saran yang mungkin dapat dijadikan bahan pertimbangan dalam upaya pengembangan lebih lanjut, yaitu: a. Bagi Universitas Budi Luhur, untuk memanfaatkan infografis interaktif ini sebagai media informasi dan promosi, serta menambah multimedia interaktif lainnya sebagai alat promosi dan promosi yang lebih modern dan menarik.

b. Bagi peneliti selanjutnya, sebaiknya membuat aplikasi HTML5 dibanding aplikasi dengan format flash untuk aplikasi seperti ini agar bisa diterapkan juga pada website dan mobile dengan baik.

c. Untuk aplikasi web yang memerlukan video dan musik disarankan tidak menggunakan program InDesign karena proses input video dan musik yang harus dimasukkan kedalam URL khusus terlebih dahulu dan tidak bisa tergabung menjadi satu dalam aplikasi.

\section{DAFTAR PUSTAKA}

[1] Resnatika, Ajeng., Sukaesih. and Kurniasih, Nuning.Peran Infografis Sebagai Media Promosi Dalam Pemanfaatan Perpustakaan. Jurnal Kajian Informasi \& Perpustakaan. 6(2), 2018, pp. 187.

[2] Saptodewo, Febrianto.Desain Infografis Sebagai Penyajian Data Menarik. Jurnal Desain. 1(3), 2014,pp. 194-195. 